\title{
Age Variance in the Survival of United States Pediatric Leukemia Patients (1973-2006)
}

\author{
L. Holmes Jr, ${ }^{1,2,3,4}$ F. Opara, ${ }^{2}$ M. Des-Vignes-Kendrick, ${ }^{5}$ and J. Hossain ${ }^{4,6}$ \\ ${ }^{1}$ American Health Research Institute, Houston, TX 77008, USA \\ ${ }^{2}$ Nemours Center for Childhood Cancer Research, Wilmington, DE 19803, USA \\ ${ }^{3}$ Epidemiology and Biostatistics Section, Orthopedic Department, Alfred I. duPont Hospital for Children, Wilmington, DE 19803, \\ USA \\ ${ }^{4}$ University of Delaware, Newark, DE 19716, USA \\ ${ }^{5}$ School of Rural Public Health, Texas A\&M, Houston, TX 77030, USA \\ ${ }^{6}$ Biomedical Research Department, Alfred I. duPont Hospital for Children, Wilmington, DE 19803, USA
}

Correspondence should be addressed to L. Holmes Jr, lhol@ahriresearch.org

Received 23 January 2012; Accepted 20 March 2012

Academic Editors: E. Clays, J. Eyles, and C. Rissel

Copyright ( $) 2012$ L. Holmes Jr et al. This is an open access article distributed under the Creative Commons Attribution License, which permits unrestricted use, distribution, and reproduction in any medium, provided the original work is properly cited.

Background. Age at diagnosis remains an important prognostic factor in pediatric leukemia. However, it is not fully understood which prognostic factors are related to its effect on survival. This study aimed to assess the effect of age at diagnosis on pediatric leukemia survival in the United States (US). Methods. We utilized the Surveillance Epidemiology and End Results (SEER) data of the diagnosed pediatric leukemia patients $(n=15215)$ from 1973-2006. Life table, Kaplan-Meier, log rank test, and Cox proportional hazard methods were used to examine the data. Results. The overall 5-year survival was $67.9 \%$. Infants and children of 18 and 19 years had the highest risk of dying, with a rapid declining risk of death at age of 1 year that continued until age of 3 years and thereafter a steady trend of increased risk of death. The increased risk of dying was associated with boys, T-cell type and more than one primary tumor, $P<0.0001$. There was significant variability in survival by the age group at diagnosis. Compared to age group $<1$ year, children of ages 1-4 years, 5-9 years, 10-14 years, and 15-19 years were 76\% (adjusted hazard ratio $(\mathrm{AHR})=0.24,99 \% \mathrm{CI}=0.21-0.28), 69 \%(\mathrm{AHR}=0.31,99 \% \mathrm{CI}=0.26-0.36), 46 \%(\mathrm{AHR}=0.54,99 \% \mathrm{CI}=0.46-0.62)$, and $18 \%(\mathrm{AHR}=0.82,99 \% \mathrm{CI}=0.70-0.95)$ less likely to die, respectively. Conclusion. The age at tumor diagnosis was a single most potent prognostic factor of childhood leukemia survival, with infants and children of age group 15-19 years experiencing the poorest survival. This significant variability persisted after adjustment for the effect of other covariates. Therefore, there is a need to identify other prognostic factors that are associated with age in order to provide a meaningful explanation of the impact of age on pediatric leukemia survival in the US.

\section{Introduction}

Previous studies have identified age at diagnosis to be an important prognostic factor in pediatric leukemia survival [1-6]. Some of these studies reported a favorable prognosis in relation to age group 1-9 years, while infants were identified with the poorest outcome followed by the 1519-year age group [2,4-6]. Survival variability by age at diagnosis reflects biologic and clinical prognostic factors associated with age [5-14]. The poorest prognosis for infants with acute lymphoblastic leukemia (ALL) may be associated with a high frequency of cases with rearrangements of the MLL gene on chromosome band 11q23 [9-11]. A study on acute lymphoblastic leukemia in infants by the Children's Cancer Study Group found increased incidence of adverse effect and failure to achieve complete remission compared with older children [12]. The conclusion from this group pointed to increase constellation of clinical features in infants at presentation such as leukocytosis, hepatosplenomegaly and hypogammaglobulinemia which predict poor outcome, restrict treatment, thus decreasing survival. The less favorable outcome for adolescents and young adults is due in 
part to the increased relative frequency of higher risk ALL subtypes (e.g., Philadelphia chromosome positive ALL and T-cell ALL) [4, 12].

The favorable prognosis of 1-9-year-old children may be related to the relatively high proportion of cases in this age range with favorable biological subtypes; that is, cases with hyperdiploid DNA content or with the TEL-AML1 gene rearrangement are more prone to survival advantage $[7,8,13-16]$. Certain clinical syndromes have been shown to provide benefit. For example, children diagnosed with Down syndrome have reported survival advantage [17-19].

Whereas previous studies have reflected on nexus between age at diagnosis and leukemia prognostics and survival consistently, there are very limited studies that tend to focus on pediatric age groups at diagnosis precisely and its specific effect on survival. In addition we are not aware of many studies conducted to provide the extent of the survival variability by the age at tumor diagnosis. Age at diagnosis is a surrogate prognostic factor in leukemia. The direct biologic and clinical correlates of age at tumor diagnosis remained to be fully understood. A generalizable assessment of age at diagnosis in leukemia survival requires a large sample and a long-term study. The SEER dataset has potentials for evaluating the age at diagnosis of childhood cancer in relation to survival. This present study used the SEER dataset, 1973-2006, and assessed the impact of age group at diagnosis on leukemia survival among children $0-19$ years. We aimed to assess the effect of age at diagnosis on survival as well as the impact of other covariates in explaining the variability in survival by age at diagnosis.

\section{Materials and Methods}

The SEER datasets from the 17 registries were used to examine the impact of age at diagnosis on survival of patients diagnosed with leukemia, and treated for the disease. While leukemia is not a homogenous cancer, we wanted to assess the effect of age at diagnosis on survival in general. This approach was taken to ensure a large sample for this study. From 1973 to 2006, there were 15,215 children diagnosed with leukemia (clinical subtypes combined).

2.1. Data Source-Surveillance Epidemiology and End Results (SEER) Cancer Registry. We used the SEER database which includes information from 17 registries. This database is estimated to represent $26 \%$ of the US population [20]. SEER has information on tumor histology, number of primary tumors, radiation therapy, surgery, survival status, and survival time, but includes no information on chemotherapy. Demographic information is available on age at tumor diagnosis, year of diagnosis, sex, and race. The SEER dataset is known to be reliable and valid for the conduct of population based studies involving cancer in the United States [20,21].

2.2. Diagnosis. Leukemia was ascertained using the International Classification of Diseases and Related Health Problems, 10th Revision (ICD-10). The clinical subtypes were also ascertained using the same classification code.

\subsection{Study Variables}

2.3.1. Age at Diagnosis. We examined the age at diagnosis of patients and extracted data from all patients 0 to 19 years of age at the time of diagnosis. Age is recorded in category, namely: (a) <1 year, (b) 1-4, (c) 5-9, (d) 10-14, and (d) 15-19 years. These age categories represent pediatric malignancies groupings used in most studies and were adopted for the purpose of this paper.

2.3.2. Year of Diagnosis. This study covered 34 years of data collected by several SEER registries (9-17 over time). The details of the SEER registries are available elsewhere [21]. We examined every year for which leukemia was diagnosed as well as mortality status of the patients. To provide some insight into the survival of these patients by group of years of diagnosis, we created five-year interval categories of the year of diagnosis (1973-1977, 1978-1982, 1983-1987, 19881992, 1993-1997, 1998-2002, 2003-2006 (Note: this last grouping 2003-2006 is a four-year interval, not five)). These categories simulate the five-year survival periods commonly used in assessing the clinical benefits of cancer therapeutics. For the purpose of the analysis, we treated year of diagnosis as a single and categorical year in order to examine the patterns of survival. Because the year of diagnosis may influence the treatment pattern and hence prognosis, as well as reflect time-dependency (time-dependent variable), we used this variable in the stratified analysis (Stratified Cox).

2.3.3. Sex. Sex in the SEER dataset and for the purpose of this study is a biological construct and refers to the classification of living things, generally as male or female according to their reproductive organs and functions assigned by their chromosomal component. We treated the male as the reference group with this dichotomous nominal variable.

2.3.4. Race. The SEER dataset collects information on race as (a) white, (b) black, (c) others, and, (d) unknown. Because of the difficulties in explaining others and unknown, we did not stress the latter two groups in the interpretation of the results in this study.

2.4. Number of Primaries. The SEER dataset collects information on the number of primary tumors as: (a) 1, (b) 2, and (c) 3 primaries. For the purpose of this study, we treated this variable as binary by creating two groups of primaries, namely (a) one primary, and (b) two or more primaries, with one primary set as the reference group in the analysis.

2.4.1. Tumor Cell Types. The cell type of leukemia is available in the SEER dataset. We extracted information on this variable and used two distinct cell types, namely, T-cell and B-cell/B-precursor.

This variable was treated as binary, with the T-cell as the reference group.

2.4.2. Information on Radiation Therapy. The SEER dataset lists information of radiation therapy in a nominal pattern. 
Radiation is grouped into (a) beam radiation (b) combination, meaning beam radiation with implant or isotopes, (c) radiation NOS, method or source not specified, (d) recommended meaning unknown if administered, (e) refused, and (f) unknown. Detailed information on the radiation therapy regimen such as dosage is not available. This variable was dichotomized into (a) radiation: yes, and (b) no radiation: no.

2.4.3. Survival Time and Status. The survival time is listed as months from the time of diagnosis to the time death from any cause. In the dataset, those who did not experience the event (death) during the follow-up time were censored. The follow-up time is listed as the duration from time of diagnosis to death from any cause or last day of the availability of survival information in the SEER registry. Therefore, the follow-up time varies, with the earlier diagnosed patients having longer follow-up times compared to those diagnosed later. For example, a patient who was diagnosed with leukemia in January 1973 and was still alive in 2006, has a maximum follow-up time of 407 months (1973-2006), while patients diagnosed in January 2006 had a maximum of 12 months follow-up time. The survival status was measured on a binary scale, with 0 (zero) for censored and 1 (one) for the event or failure.

2.5. Statistical Analyses. A preanalysis screening was performed to examine missing values, as well as outliers. Life table analysis was carried out to examine the incidence of dying from leukemia by age at diagnosis in SEER dataset and to construct a five-year interval survival percentage of pediatric leukemia patients by age group. Study variables were summarized by age group at diagnosis. Categorical variables were described using frequency and percentages, while continuous variables were summarized using mean and standard deviation, or median and interquartile range (IQR). Pearson chi-square statistic was used to examine the distribution of study characteristics between age groups at tumor diagnosis as a categorical variable, while chi-square trend analysis was performed to examine the trend of study variables over the age group at diagnosis. A univariable Cox proportional hazard model was performed to assess the effect of an individual covariate, including age group at diagnosis on survival. We utilized the univariable Cox proportional hazard method and obtained the hazard ratio (relative risk of dying that reflects the magnitude of the association between covariate and survival) as a point estimate and $99 \%$ confidence interval (CI) as well as the $P$ value for statistical stability. Because there are many factors that influence survival of a cohort of cancer patients treated for the disease, we examined the effect of age at diagnosis in combination with other confounding factors using multivariable Cox proportional hazard model. In this regard, we performed two adjusted models because of many missing values for the variable tumor cell type, one without and the other with tumor cell types, and provided two results in this study. The reason for using two adjusted models was due to missing values in the tumor cell type variable and analyses were based on the available data only. For both adjusted models, stratified analyses were performed by the single year of diagnosis which allowed us to compare hazard of a given year with the corresponding year's baseline hazard. Also, we graphically illustrated survival estimates in the overall cohort as well as by age group using the Kaplan-Meier survival curves and survival proportion curve from the life table. The significance level was 0.01 and all tests were two-tailed. The Statistical Package for Social Sciences (SPSS), version 17.0, SPSS Inc., Chicago, IL and STATA (STATACorp) version 11.0, College Station, TX, were used to perform the analyses.

\section{Results}

Between 1973-2006, childhood leukemia, ages 0-19 years was most diagnosed at ages $2(11.9 \%)$ and $3(11.4 \%)$, while the lowest diagnosis was observed in ages of $17(3.1 \%)$ and 18(3.1\%). Table 1(a) demonstrates the number of patients who survived, those who died, and the incidence rate of dying per thousand person-month between 1973 and 2006 by age at diagnosis. The incidence rate of dying was highest for children diagnosed at 18 and 19 as well as those diagnosed at age less than 1 year. In contrast, the incidence rate of dying was lowest for the children diagnosed at 2-4 years. There was a rapid decline in hazard of dying from those who were diagnosed at age of $<1$ year $(9.86 \%$ per 1000 personmonth) compared to those children who were diagnosed at age of 1 year (3.33\% per 1000 person-month). The declining trend in mortality continued until the age of 3 years at diagnosis (1.60\% per 1000 person-month) and then began started increasing gradually from age of 4 years at diagnosis, with worst hazard of dying at ages of diagnosis 18-19 years. Table 1(b) presents demographics and other study variables characterized by age group at diagnosis. Boys and girls did differ significantly by age at diagnosis $\left(\chi^{2}=49.7(4)\right.$, $P<0.0001)$. There was an apparent increasing trend in the proportion of boys over age at diagnosis $\left(\chi^{2}\right.$ for trend $=30.6$ (1), $P<0.0001)$. Also, the distribution of patients in different races differed significantly by the age group at diagnosis $\left(\chi^{2}\right.$ $=52.2(12), P<0.0001)$, with the least percent of diagnosed leukemia patients being black (6.4\%) shown in age group 1-4 years at diagnosis, where survival experience is highest. The number of primaries did differ as well with age group at diagnosis $\left(\chi^{2}=57.9(4), P<0.0001\right)$, with a significant increasing trend in patients diagnosed with more than one primary tumor $\left(\chi^{2}\right.$ for trend $\left.=56.9(1), P<0.0001\right)$. The tumor cell type showed a significant difference by age group at diagnosis $\left(\chi^{2}=321.3(4), P<0.0001\right)$ with a strong increasing trend observed in T-cell type $\left(\chi^{2}\right.$ trend $=272.1(1)$, $P<0.0001)$. The receipt of radiation therapy differed by age group at diagnosis $\left(\chi^{2}=190.5(4), P<0.0001\right)$ illustrated a strong increasing trend by the age group at diagnosis $\left(\chi^{2}\right.$ trend $=149.0(1), P<0.0001)$. A significant difference in the year of diagnosis by age group at diagnosis was shown, with an apparent increase in tumor diagnosed, $\left(\chi^{2}=61.8\right.$ (24), $P<0.0001)$. A significant difference was observed in the age group at diagnosis with respect to the survival status. The children diagnosed at ages $<1$ year and $15-19$ years had the worst mortality outcome, $\left(\chi^{2}=1043.3\right.$ (4), $\left.P<0.0001\right)$. Table 1(c) shows a 5-year interval of survival percentage of 
TABLE 1

(a) Risk (hazard) of dying in leukemia patients (1973-2006 SEER dataset) by age at diagnosis

\begin{tabular}{lccc}
\hline Age at diagnosis (yrs) & Alive No. $(\%)$ & Dead No. $(\%)$ & Incidence rate of dying per 1000 person-month \\
\hline 0 & $375(48.6)$ & $396(51.4)$ & 9.86 \\
1 & $834(71.0)$ & $340(29.0)$ & 1.33 \\
2 & $1468(81.1)$ & $341(18.9)$ & 1.60 \\
3 & $1430(82.7)$ & $300(17.3)$ & 1.87 \\
4 & $1099(81.5)$ & $249(18.5)$ & 2.04 \\
5 & $762(78.4)$ & $210(21.6)$ & 2.44 \\
6 & $544(74.7)$ & $184(25.3)$ & 2.94 \\
7 & $477(72.9)$ & $177(27.1)$ & 3.86 \\
8 & $406(72.4)$ & $155(27.6)$ & 3.61 \\
10 & $349(69.0)$ & $157(31.0)$ & 4.05 \\
10 & $320(65.7)$ & $167(34.3)$ & 4.92 \\
11 & $312(64.9)$ & $169(35.1)$ & 5.12 \\
12 & $325(62.6)$ & $194(37.4)$ & 5.70 \\
13 & $299(57.9)$ & $217(42.1)$ & 5.82 \\
14 & $330(61.0)$ & $211(39.0)$ & 7.20 \\
15 & $268(51.6)$ & $251(48.4)$ & 6.20 \\
16 & $293(55.6)$ & $234(44.4)$ & 8.81 \\
17 & $230(48.7)$ & $242(51.3)$ & 10.22 \\
18 & $196(42.2)$ & $269(57.8)$ & 10.77 \\
19 & $187(43.0)$ & $248(57.0)$ &
\end{tabular}

Abbreviation. SEER: Surveillance Epidemiology and End Results.

(b) Demographics and other study variables characterization by age group at diagnosis of pediatric patients with leukemia, SEER registry $1973-2006$

\begin{tabular}{|c|c|c|c|c|c|c|c|}
\hline \multirow{2}{*}{ Covariates } & \multicolumn{5}{|c|}{ Age group at diagnosis (yrs) } & \multirow{2}{*}{$\chi^{2}(\mathrm{df})$} & \multirow{2}{*}{$P$ value } \\
\hline & $>1$ & $1-4$ & $5-9$ & $10-14$ & $15-19$ & & \\
\hline Sex & & & & & & $49.7(4)$ & $<0.0001$ \\
\hline Male & $386(50.1)$ & $3411(56.3)$ & $1871(54.7)$ & $1450(57.0)$ & $1504(62.2)$ & & \\
\hline Female & $385(49.9)$ & $2649(43.7)$ & $1550(45.3)$ & $1094(43.0)$ & $914(37.8)$ & & \\
\hline Race & & & & & & $52.2(12)$ & $<0.0001$ \\
\hline White & $623(80.8)$ & $5000(82.5)$ & $2776(81.1)$ & $2048(80.5)$ & $1988(82.2)$ & & \\
\hline Black & $71(9.2)$ & $389(6.4)$ & $283(8.3)$ & $261(10.3)$ & $208(8.6)$ & & \\
\hline Others & $75(9.7)$ & $651(10.7)$ & $345(10.1)$ & $223(8.8)$ & $212(8.8)$ & & \\
\hline Unknown & $2(0.3)$ & $21(0.3)$ & $17(0.5)$ & $12(0.5)$ & $10(0.4)$ & & \\
\hline No. of primaries & & & & & & $57.9(4)$ & $<0.0001$ \\
\hline 1.0 & $769(99.7)$ & $6004(99.1)$ & $3361(98.2)$ & $2494(98.0)$ & $2346(97.0)$ & & \\
\hline$\geq 2.0$ & $2(0.3)$ & $57(0.9)$ & $60(1.8)$ & $50(2.0)$ & $72(3.0)$ & & \\
\hline Cell type & & & & & & $321.3(4)$ & $<0.0001$ \\
\hline T-cell & $13(7.3)$ & $168(6.5)$ & $293(19.6)$ & $244(25.5)$ & $199(25.3)$ & & \\
\hline B-cell, B-precursor & $166(92.7)$ & $2407(93.5)$ & $1199(80.4)$ & $711(74.5)$ & $588(74.7)$ & & \\
\hline Radiation & & & & & & $190.5(4)$ & $<0.0001$ \\
\hline Yes & $90(11.7)$ & $846(14.0)$ & $581(17.0)$ & $631(24.8)$ & $517(21.4)$ & & \\
\hline No & $681(88.3)$ & $5215(86.0)$ & $2840(83.0)$ & $1913(75.2)$ & $1901(78.6)$ & & \\
\hline Year of diagnosis & & & & & & $61.8(24)$ & $<0.0001$ \\
\hline $1973-77$ & $47(6.1)$ & $442(7.3)$ & $268(7.8)$ & $201(7.9)$ & $213(8.8)$ & & \\
\hline $1978-82$ & $61(7.9)$ & $430(7.1)$ & $248(7.2)$ & $206(8.1)$ & $212(8.8)$ & & \\
\hline $1983-87$ & $68(8.8)$ & $506(8.3)$ & $271(7.9)$ & $223(8.8)$ & $193(8.0)$ & & \\
\hline 1988-92 & $71(9.2)$ & $649(10.7)$ & $382(11.2)$ & $213(8.4)$ & $211(8.7)$ & & \\
\hline 1993-97 & $109(14.1)$ & $994(16.4)$ & $519(15.2)$ & $357(14.0)$ & $316(13.1)$ & & \\
\hline $1998-02$ & $203(23.3)$ & $1501(24.8)$ & $903(26.4)$ & $657(25.8)$ & $623(25.8)$ & & \\
\hline $2003-06$ & $212(27.5)$ & $1539(25.4)$ & $830(24.3)$ & $687(27.0)$ & $650(26.9)$ & & \\
\hline
\end{tabular}


(b) Continued.

\begin{tabular}{lcccccc}
\hline Covariates & \multicolumn{7}{c}{ Age group at diagnosis (yrs) } & \multicolumn{1}{c}{$\chi^{2}(\mathrm{df})$} & $P$ value \\
& $>1$ & $1-4$ & $5-9$ & $10-14$ & $15-19$ & $<0.0001$ \\
\hline $\begin{array}{l}\text { Survival time (months) } \\
\quad \text { Median }\end{array}$ & 33.0 & - & 398.0 & 307.0 & 44.0 & \\
$\quad$ Mean (Sd) & $160.6(7.8)$ & $308.0(2.6)$ & $279.9(3.7)$ & $224.9(4.7)$ & $167.3(4.5)$ & $1043.3(4)$ \\
Mortality status & & & & & & \\
$\quad$ Alive & $375(48.6)$ & $4831(79.7)$ & $2538(74.2)$ & $1586(62.3)$ & $1174(48.6)$ & \\
$\quad$ Dead & $396(51.4)$ & $1230(20.3)$ & $883(25.8)$ & $958(37.7)$ & $1244(51.4)$ & \\
\hline
\end{tabular}

Notes and Abbreviations. The significance level is 0.01, CI: confidence interval, df: degrees of freedom. The median survival time for age group 1-4 years was not estimated as $50 \%$ of patients did not die in this group at any point of time (that is the KM estimator for $1-4$ age group never reaches a probability of dying greater than 0.5$)$.

(c) Five-year interval survival percentage of pediatric leukemia patients overall and by age group at diagnosis

\begin{tabular}{|c|c|c|c|c|c|c|}
\hline \multirow{2}{*}{$\begin{array}{l}\text { Survival time interval } \\
\text { (months) }\end{array}$} & \multirow{2}{*}{ Overall survival (\%) } & \multicolumn{5}{|c|}{ Survival percentage by age group (years) at diagnosis } \\
\hline & & $<1$ & $1-4$ & $5-9$ & $10-14$ & $15-19$ \\
\hline $0-60$ & 67.9 & 43.3 & 79.8 & 75.3 & 60.4 & 44.8 \\
\hline $60-120$ & 63.0 & 40.1 & 75.5 & 69.1 & 54.9 & 39.8 \\
\hline $120-180$ & 61.0 & 39.5 & 73.5 & 66.8 & 52.4 & 38.1 \\
\hline $180-240$ & 59.6 & 37.6 & 72.2 & 64.9 & 51.0 & 37.6 \\
\hline $240-300$ & 58.9 & 36.7 & 71.5 & 63.9 & 49.7 & 37.6 \\
\hline $300-360$ & 57.1 & 36.7 & 70.3 & 62.8 & 48.0 & 35.8 \\
\hline $360-420$ & 55.6 & 36.7 & 69.1 & 60.5 & 44.8 & 32.4 \\
\hline
\end{tabular}

children with leukemia, stratified by age group at diagnosis. The 5-year survival was lowest in the group $<1$ year of age and was the highest in the group 1-4 years of age. However, the 10-year survival was lowest in the group 15-19 but was highest in the group 1-4 years of age. The age group 1519 years continued to show the lowest survival for longer time, while the age group of 1-4 years showed a persistent a highest survival. The 20 -year survival was equally lowest in the groups $<1$ year and 15-19 years. A similar pattern was observed in the 25- and 30-year-survival.

Table 2 shows the factors associated with mortality including age at diagnosis. In this univariable Cox proportional hazard model, survival varied significantly by age at diagnosis using $<1$ year of age as reference group, except age group of 15-19 years. Children 1 to 4 years were $76 \%$ less likely to die from leukemia compared to age $<1$ year, $\mathrm{HR}=$ $0.24,99 \% \mathrm{CI}, 0.22-0.30$. Similarly, children 5 to 9 years were $67 \%$ less likely to die $(\mathrm{HR}=0.33,99 \%$ CI $0.28-0.39)$. Also, children aged 10-14 were $44 \%$ less likely to die compared to the children $<1$ year of age $(\mathrm{HR}=0.56,99 \%$ CI $0.0 .48-0.66)$. However, there was no significant difference in mortality by age at diagnosis comparing children $<1.0$ year to children $15-19$ years, $(\mathrm{HR}=0.89,99 \%$ CI $0.77-1.04)$. Sexes did differ regarding mortality, with girls compared to boys less likely to die from leukemia, HR $=0.86,99 \% \mathrm{CI}=0.80-0.93$. Similarly there was a statistically significant difference in mortality outcome by race. Specifically black children were 54\% more likely to die relative to white children $(\mathrm{HR}=1.54,99 \% \mathrm{CI}$, 1.36-1.74). Children with two or more primaries showed higher risk of dying compared to those diagnosed with only one primary, $\mathrm{HR}=1.75,95 \%$ CI $1.40-2.22$. Radiation as a monotherapy did not improve survival, and children who did not receive radiation compared to those who did had a significant $16 \%$ decreased risk of dying, $\mathrm{HR}=0.84,99 \%$ $\mathrm{CI}=0.77-0.92$. The tumor cell type showed a significant variance with respect to survival, and the children diagnosed with a B-cell/B-precursor were 51\% less likely to die relative to children who were diagnosed with $\mathrm{T}$-cell type, $\mathrm{HR}=0.49$, 99\% CI 0.41-0.59.

Since, there are other factors that can influence the survival of children with cancer treatment; we assessed the prognostic effect of these factors as confounding variable on the effect of age of the children at time of diagnosis on leukemia survival. We built a multivariable model in order to control simultaneously for the effect of these confounding factors.

In assessing the confounding effect of race, sex, radiation therapy, and the number of primaries, and stratifying by the year of diagnosis, the association between age at diagnosis and leukemia survival among children persisted (Table 3(a)). Compared to age group $<1$ year, children of ages $1-4$ years, 5-9 years, 10-14 years, and 15-19 years were 76\% (AHR $=0.24,99 \% \mathrm{CI}=0.21-0.28), 69 \%(\mathrm{AHR}=0.31,99 \% \mathrm{CI}=$ $0.26-0.36), 46 \%(\mathrm{AHR}=0.54,99 \% \mathrm{CI}=0.46-0.62)$, and $18 \%(\mathrm{AHR}=0.82,99 \% \mathrm{CI}=0.70-0.95)$ less likely to die, respectively. Similarly, after further adjustment including the cell type of leukemia (T-cell versus B-cell/B-precursors) in the model, the significant relationship between age at diagnosis and pediatric leukemia survival furthermore persisted (Table 3(b)).

Figure 1 shows the proportion of children in age groups with leukemia surviving by 5 -year interval. The KaplanMeier survival estimate (Figure 2) shows distinctive survival in the age group at diagnosis, $P<0.0001$ (log rank test). 
TABLe 2: Mortality associated with age at diagnosis and other factors in pediatric patients with leukemia, 1973-2006.

\begin{tabular}{|c|c|c|c|}
\hline Covariates & Hazard ratio (HR) & $99 \% \mathrm{CI}$ & $P$ \\
\hline \multicolumn{4}{|l|}{ Age at diagnosis (yrs) } \\
\hline$<1.0$ & 1.00 & ref & ref \\
\hline $1.0-4.0$ & 0.26 & $0.22-0.30$ & $<0.0001$ \\
\hline $5.0-9.0$ & 0.33 & $0.28-0.39$ & $<0.0001$ \\
\hline $10.0-14.0$ & 0.56 & $0.48-0.66$ & $<0.0001$ \\
\hline $15.0-19.0$ & 0.89 & $0.77-1.04$ & 0.05 \\
\hline \multicolumn{4}{|l|}{ Sex } \\
\hline Male & 1.00 & ref & ref \\
\hline Female & 0.86 & $0.80-0.93$ & $<0.0001$ \\
\hline \multicolumn{4}{|l|}{ Race } \\
\hline White & 1.00 & ref & ref \\
\hline Black & 1.54 & $1.36-1.74$ & $<0.0001$ \\
\hline \multicolumn{4}{|l|}{ Cell type } \\
\hline T-cell & 1.00 & ref & ref \\
\hline B-cell, B-precursor & 0.49 & $0.41-0.59$ & $<0.0001$ \\
\hline \multicolumn{4}{|l|}{ Year of diagnosis } \\
\hline 1973-1977 & 1.00 & ref & ref \\
\hline 1978-1982 & 0.73 & $0.64-0.84$ & $<0.0001$ \\
\hline 1983-1987 & 0.60 & $0.52-0.69$ & $<0.0001$ \\
\hline 1988-1992 & 0.42 & $0.36-0.48$ & $<0.0001$ \\
\hline 1993-1997 & 0.38 & $0.33-0.43$ & $<0.0001$ \\
\hline 1998-2002 & 0.33 & $0.29-0.37$ & $<0.0001$ \\
\hline 2003-2006 & 0.29 & $0.25-0.34$ & $<0.0001$ \\
\hline \multicolumn{4}{|l|}{ No. of primaries } \\
\hline 1.0 & 1.00 & ref & ref \\
\hline$\geq 2.0$ & 1.75 & $1.40-2.20$ & $<0.0001$ \\
\hline \multicolumn{4}{|l|}{ Beam radiation } \\
\hline Yes & 1.00 & ref & ref \\
\hline No & 0.84 & $0.77-0.92$ & $<0.0001$ \\
\hline
\end{tabular}

Notes and Abbreviations. The significance level was 0.01. CI: confidence interval.

\section{Discussion}

Leukemia is a hematogeneous malignancy, affecting blood and bone marrow. It is a commonly diagnosed tumor in pediatric population all over the world, accounting for an approximately $35 \%$ of all childhood malignancies in the US [22]. The five-year survival rate for children diagnosed with leukemia and subsequently treated is approximately $70 \%$ [22]. Over the years, survival from this malignancy has improved dramatically among children due precisely to the improvement in treatment, early diagnosis, and favoring prognosis $[4,22]$. The age at diagnosis is a prognostic factor in childhood leukemia. But, this variable or prognostic factor has not been precisely assessed in terms of the extent of its effect on survival. Likewise, it is unclear which surrogates may predict its impact on survival.

This present study was conducted to assess the effect of age at diagnosis on the survival of children diagnosed with leukemia in general. There were several findings from this study. First, there was a significant variation in survival by age group at diagnosis, with infants and children 15-19 years tending to show the worst survival outcome. Secondly, survival advantage was most pronounced in age group 1-4 years (with the best survival for age group 2-3 years) with a declining survival pattern after age of 4 years. Thirdly, sex, race, number of primaries, receipt of radiation therapy, and tumor cell type were potential predicators of survival besides the age at tumor diagnosis.

Previous studies on leukemia that assessed factors predicting survival were, in most cases, based on small sample size and short-term followup. In addition most studies including ours tend to be heterogeneous, thus limiting the ability of these studies to assess the effect of age on leukemia subtypes survival. The SEER data set used in this study provided us with the opportunity to properly assess the effect of age at diagnosis on survival. We used a long-term assessment, 
TABLE 3

(a) Mortality associated with age at diagnosis in pediatric patients with leukemia, 1973-2006, in an adjusted multivariable Cox proportional hazard model stratified by the year of diagnosis

\begin{tabular}{|c|c|c|c|}
\hline Covariates & Adjusted hazard ratio (AHR) & $99 \% \mathrm{CI}$ of $\mathrm{HR}$ & $P$ \\
\hline \multicolumn{4}{|c|}{ Age at diagnosis (yrs) } \\
\hline$<1.0$ & 1.0 & ref & ref \\
\hline $1.0-4.0$ & 0.24 & $0.21-0.28$ & $<0.0001$ \\
\hline $5.0-9.0$ & 0.31 & $0.26-0.36$ & $<0.0001$ \\
\hline $10.0-14.0$ & 0.54 & $0.46-0.62$ & $<0.0001$ \\
\hline $15.0-19.0$ & 0.82 & $0.70-0.95$ & 0.001 \\
\hline \multicolumn{4}{|l|}{ Sex } \\
\hline Boys & 1.0 & ref & ref \\
\hline Girls & 0.87 & $0.81-0.94$ & $<0.0001$ \\
\hline \multicolumn{4}{|l|}{ Race } \\
\hline White & 1.0 & ref & ref \\
\hline Black & 1.47 & $1.29-1.65$ & $<0.0001$ \\
\hline \multicolumn{4}{|c|}{ No. of primaries } \\
\hline 1.0 & 1.0 & ref & ref \\
\hline$\geq 2.0$ & 1.30 & $1.03-1.63$ & 0.004 \\
\hline \multicolumn{4}{|l|}{ Radiation } \\
\hline Yes & 1.0 & ref & ref \\
\hline No & 1.22 & $1.11-1.34$ & $<0.0001$ \\
\hline
\end{tabular}

Notes and Abbreviations. The significance level was 0.01. CI: Confidence interval.

(b) Mortality associated with age at diagnosis in pediatric patients with Leukemia, 1973-2006, in an adjusted multivariable Cox proportional hazard model stratified by the year of diagnosis in a subset of data with cell type only information

\begin{tabular}{|c|c|c|c|}
\hline Covariates & AHR & $99 \% \mathrm{CI}$ of $\mathrm{HR}$ & $P$ \\
\hline \multicolumn{4}{|l|}{ Age at diagnosis (yrs) } \\
\hline$<1.0$ & 1.0 & ref & ref \\
\hline $1.0-4.0$ & 0.14 & $0.10-0.20$ & $<0.0001$ \\
\hline $5.0-9.0$ & 0.21 & $0.15-0.30$ & $<0.0001$ \\
\hline $10.0-14.0$ & 0.38 & $0.27-0.54$ & $<0.0001$ \\
\hline $15.0-19.0$ & 0.65 & $0.46-0.91$ & 0.001 \\
\hline \multicolumn{4}{|l|}{ Sex } \\
\hline Boys & 1.0 & ref & ref \\
\hline Girls & 0.86 & $0.72-1.01$ & 0.018 \\
\hline \multicolumn{4}{|l|}{ Race } \\
\hline White & 1.0 & ref & ref \\
\hline Black & 1.45 & $1.10-1.93$ & 0.001 \\
\hline \multicolumn{4}{|l|}{ No. of primaries } \\
\hline 1.0 & 1.0 & ref & ref \\
\hline$\geq 2.0$ & 1.79 & $0.93-3.45$ & 0.022 \\
\hline \multicolumn{4}{|l|}{ Radiation } \\
\hline Yes & 1.0 & ref & ref \\
\hline No & 1.01 & $0.82-1.24$ & 0.945 \\
\hline \multicolumn{4}{|l|}{ Cell type } \\
\hline T-cell & 1.0 & ref & ref \\
\hline B-cell, B-precursor & 0.72 & $0.59-0.88$ & $<0.0001$ \\
\hline
\end{tabular}

Notes and abbreviations. The significance level was 0.01. CI: confidence interval.

Cell type information is available since 1980 and for only total of 5988 patients (917 T-cell and 5071 B-cell/B-precursor). The proportion of B-cell/Bprecursor increases precipitously over the year of diagnosis starting with $0.0 \%$ in 1980 to $89 \%$ in 2006 . The above table illustrates an adjusted analysis with cell types restricting the sample size to 5988 patients. AHR: adjusted hazard ratio; ref: referent group. 


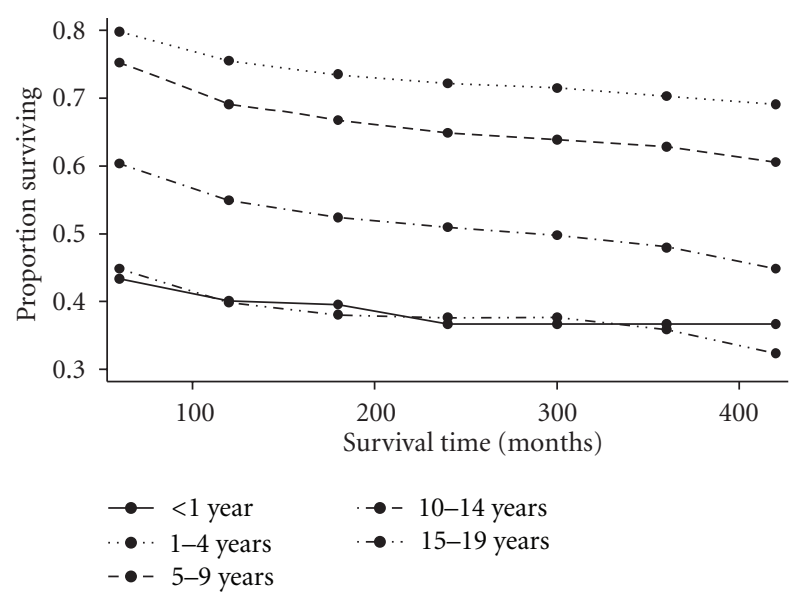

FIGURE 1: Five-year interval survival probability by age group in months.

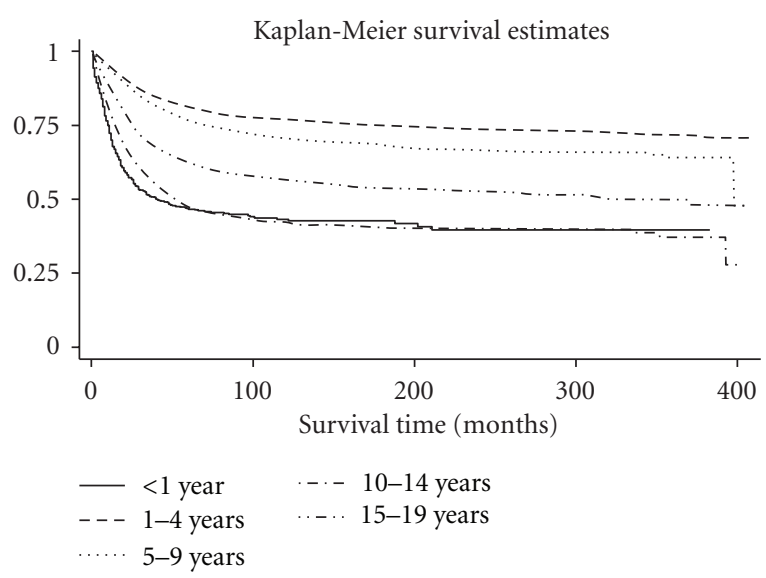

FIGURE 2: Kaplan-Meier survival estimates by age group in months.

a large sample size, and an adequate statistical modeling, adjusting for the effect of known potential confounders on survival.

We have demonstrated that age at diagnosis remains a single potent predictor of survival in pediatric leukemia in US. Children aged 2-3 years showed the most survival advantage. Children $<1$ year of age as well as children of 15-19 years showed the poorest survival, with a downward survival pattern over increasing age after 4 years. Previous studies showed biological and clinical relation to the survival variation with age at diagnosis in part that we discussed in Introduction [4-19]. There is another biologic plausibility in the observed poor survival encountered by children $<1$ year of age. The observed poorer survival in this age group may be related to immature immune system [23-25]. Children $<6$ months of age are immune-compromised due to the inability of their plasma cells to generate a therapeutic antibody such as IgG. Consequently such immune system is not able to mount a response to tumor specific antigen, which results in the absence of immunologic surveillance to tumor specific antigen [23-25].
It is however not very clear why survival declined with an increased age of diagnosis after 4 years of age, with poorest survival experience among children in 15-19 years of age group. Nonetheless, there is a partial explanation in our dataset as there is an increasing trend in proportion of boys, and patients with T-cell types, and more than one number of primary tumors with an increased age (Table 1(b)). These three factors were associated with poor survival in our population-based sample (Table 2). After adjustment for these prognostic factors along with race and the receipt of radiation therapy, the age variability in survival of childhood leukemia persisted (Tables 3(a) and $3(\mathrm{~b})$ ). Pediatric leukemia, being a malignancy confined to blood cells in the spongy region of the bone marrow, may show survival variation that is age-related with respect to treatment. Often these therapeutics include the combination of chemotherapy, radiation therapy, and transplant which may either act together towards synergism or provide adverse reaction, thus compromising cancer therapeutics.

Given the variability in the length of follow-up, since the followup time for those who entered the study in 1973 varied substantially from those who entered the study in 2006, we stratified the analysis by the year of diagnosis. This approach ensured the removal of this variability in our estimation of the survival time. In spite of these statistical strategies, the age at diagnosis remained a single potent predictor of survival in pediatric leukemia (Table 3(b)). Indeed, age at diagnosis is a surrogate but associated with an important biologic and tumor-related prognostic factor. Therefore, inability to identify these factors will continue to limit our capacity to explain the effect of age at diagnosis on pediatric leukemia. A population-based study using similar dataset (SEER) examined the incidence and mortality trends in the US from 1973-1998 found survival differences by age at diagnosis.

Previous studies have assessed tumor cell types as important prognostic factor in leukemia [4-19, 25-27]. Others have considered and reported the effect of race [28$30]$, number of primaries $[27,31]$, and radiation therapies [32], chemotherapy [33-35], sex [27, 32, 36-39]. Most of these factors were assessed by this present study and were found to be associated with survival. Because previous studies were methodologically limited, we benefited from these limitations by addressing few of them with the intent to provide valid evidence on the effect of the age at diagnosis on leukemia survival. The overall five-year survival reported by us in our pediatric population is higher than that presented by the European Cancer Study Group (EUROCARE-4) in which survival was $57 \%$ but varied across geography. The report showed increasing poorer survival with age, which was associated with the differences in tumor management by age. Participants $>50$ years in this cohort were less likely to receive optimal care as well as diagnostic workup [40]. Children younger than 20 years were observed to have a $15 \%$ increase in the 5-year survival rates for both ALL and AML when comparing the two 10-year periods of 1974-1983 and 1984-1993. In contrast, there was little overall improvement in survival for adults 45 years and older. In particular, there was a notable decrease in the overall 5-year survival for blacks 
older than 65 years and for black males older than 44 years [41].

Supporting further our findings on cell types, sex, age, and race is the recent study in the US population [42]. This study found most subtypes of acute myeloid leukemia (AML) and acute lymphoblastic leukemia/lymphoma (ALL/L) to be more common among males, from twice higher incidence of T-cell ALL/L among males than among females (incidence rate ratio $(\mathrm{IRR})=2.20)$ to nearly equal IRs of acute promyelocytic leukemia (APL); IRR = 1.08). Relative to nonHispanic whites, Hispanics had significantly higher incidence of B-cell ALL/L (IRR = 1.64) and APL (IRR = 1.28); blacks had lower IRs of nearly all AL subtypes. Like our finding, the B-cell ALL/L had more favorable survival than T-cell ALL/L among the young; while the contrast was observed at older ages. Finally, we recently pointed out the survival advantage of girls in pediatric leukemia [43]. The distinct survival patterns in these studies are suggestive of more etiologic investigations, treatment advances and prognosis.

In spite of these, this current study is not without limitation. First, we used the SEER dataset with varying follow-up time. However, our results are not limited by this variability, since we stratified the analysis by the year of diagnosis. Secondly, our results may be driven in part by unmeasured confounding, since there are several tumor prognostic factors that were not available in the SEER dataset for assessment and adjustment. Thirdly, like in all epidemiologic investigations results may be influenced partly by residual confounding, since residual confounding is never removed no matter how sophisticated statistical modeling performed.

In summary, the age at diagnosis remains a single potent predictor of pediatric leukemia survival; however, it is a surrogate prognostic factor, but it is related to biological/clinical prognostic factors. This study adjusted for the effect of some of these factors, but the survival variability by the age at diagnosis persisted. Therefore, there is a need to identify prognostic factors that are associated with age in order to provide a meaningful explanation of the impact of age at tumor diagnosis on pediatric leukemia survival. Therefore, because of the heterogeneity of leukemia, the application of these findings in patient conference/counseling requires cautious interpretation.

\section{References}

[1] H. N. Sather, "Age at diagnosis in childhood acute lymphoblastic leukemia," Medical and Pediatric Oncology, vol. 14, no. 3, pp. 166-172, 1986.

[2] D. K. H. Webb, G. Harrison, R. F. Stevens, B. G. Gibson, I. M. Hann, and K. Wheatley, "Relationships between age at diagnosis, clinical features, and outcome of therapy in children treated in the Medical Research Council AML 10 and 12 trials for acute myeloid leukemia," Blood, vol. 98, no. 6, pp. 17141720, 2001.

[3] B. I. Razzouk, E. Estey, S. Pounds et al., "Impact of age on outcome of pediatric acute myeloid leukemia: a report from 2 institutions," Cancer, vol. 106, no. 11, pp. 2495-2502, 2006.

[4] NCI, "SEER Cancer statistics Review 1975-2006," NCI, 2010, http://seer.cancer.gov/csr/1975_2006/index.html.
[5] U. Creutzig, T. Büchner, M. C. Sauerland et al., "Significance of age in acute myeloid leukemia patients younger than 30 years: a common analysis of the pediatric trials AML-BFM 93/98 and the adult trials AMLCG 92/99 and AMLSG HD93/98A," Cancer, vol. 112, no. 3, pp. 562-571, 2008.

[6] B. J. Lange, F. O. Smith, J. Feusner et al., "Outcomes in CCG2961, a Children's Oncology Group phase 3 trial for untreated pediatric acute myeloid leukemia: a report from the Children's Oncology Group," Blood, vol. 111, no. 3, pp. 1044-1053, 2008.

[7] R. Trueworthy, J. Shuster, T. Look et al., "Ploidy of lymphoblasts is the strongest predictor of treatment outcome in Bprogenitor cell acute lymphoblastic leukemia of childhood: a Pediatric Oncology Group study," Journal of Clinical Oncology, vol. 10, no. 4, pp. 606-613, 1992.

[8] J. E. Rubnitz, M. P. Link, J. J. Shuster et al., "Frequency and prognostic significance of HRX rearrangements in infant acute lymphoblastic leukemia: a Pediatric Oncology Group study," Blood, vol. 84, no. 2, pp. 570-573, 1994.

[9] J. M. Hilden, J. L. Frestedt, R. O. Moore et al., "Molecular analysis of infant acute lymphoblastic leukemia: MLL gene rearrangement and reverse transcriptase-polymerase chain reaction for $\mathrm{t}(4 ; 11)(\mathrm{q} 21 ; \mathrm{q} 23)$," Blood, vol. 86, no. 10, pp. 38763882, 1995.

[10] J. E. Rubnitz, J. J. Shuster, V. J. Land et al., "Case-control study suggests a favorable impact of TEL rearrangement in patients with B-lineage acute lymphoblastic leukemia treated with antimetabolite-based therapy: a Pediatric Oncology Group study," Blood, vol. 89, no. 4, pp. 1143-1146, 1997.

[11] G. Reaman, P. Zeltzer, and W. A. Bleyer, "Acute lymphoblastic leukemia in infants less than one year of age: a cumulative experience of the Childrens Cancer Study Group," Journal of Clinical Oncology, vol. 3, no. 11, pp. 1513-1521, 1985.

[12] A. Arican, N. Ozbek, V. Baltaci, and M. Haberal, "Philadelphia chromosome(+) T-cell acute lymphoblastic leukaemia after renal transplantation," Nephrology Dialysis Transplantation, vol. 14, no. 8, pp. 2054-2055, 1999.

[13] J. E. Rubnitz, J. R. Downing, C. H. Pui et al., "TEL gene rearrangement in acute lymphoblastic leukemia: a new genetic marker with prognostic significance," Journal of Clinical Oncology, vol. 15, no. 3, pp. 1150-1157, 1997.

[14] C. M. Niemeyer, M. Arico, G. Basso et al., "Chronic myelomonocytic leukemia in childhood: a retrospective analysis of 110 cases. European Working Group on Myelodysplastic Syndromes in Childhood (EWOG-MDS)," Blood, vol. 89, no. 10, pp. 3534-3543, 1997.

[15] S. J. Passmore, J. M. Chessells, H. Kempski, I. M. Hann, P. A. Brownbill, and C. A. Stiller, "Paediatric myelodysplastic syndromes and juvenile myelomonocytic leukaemia in the UK: a population-based study of incidence and survival," British Journal of Haematology, vol. 121, no. 5, pp. 758-767, 2003.

[16] B. J. Lange, N. Kobrinsky, D. R. Barnard et al., "Distinctive demography, biology, and outcome of acute myeloid leukemia and myelodysplastic syndrome in children with Down syndrome: Children's Cancer Group Studies 2861 and 2891," Blood, vol. 91, no. 2, pp. 608-615, 1998.

[17] U. Creutzig, D. Reinhardt, S. Diekamp, M. Dworzak, J. Stary, and M. Zimmermann, "AML patients with Down syndrome have a high cure rate with AML-BFM therapy with reduced dose intensity," Leukemia, vol. 19, no. 8, pp. 1355-1360, 2005.

[18] A. S. Gamis, W. G. Woods, T. A. Alonzo et al., "Increased age at diagnosis has a significantly negative effect on outcome in children with Down syndrome and acute myeloid leukemia: a 
report from the Children's Cancer Group study 2891," Journal of Clinical Oncology, vol. 21, no. 18, pp. 3415-3422, 2003.

[19] NCI, "Surveillance, epidemiology and end results (SEER) program web site, data quality," 2010, http://seer.cancer.gov/ about/quality.html.

[20] X. Du, J. L. Freeman, and J. S. Goodwin, "Information on radiation treatment in patients with breast cancer: the advantages of the linked Medicare and SEER data," Journal of Clinical Epidemiology, vol. 52, no. 5, pp. 463-470, 1999.

[21] "Ped-Onc resource center," 2010, http://www.acor.org/pedonc/diseases/leuk.html.

[22] S. H. E. Kaufmann, R. Meclzhitov, and S. Gordon, The Innate Immune Response to Infection, ASM Press, Washington, DC, USA, 2004.

[23] J. Brostoff, A. Gray, D. K. Male, and I. M. Roitt, Case Studies in Immunology: Companion to Immunology, 5th edition, 1998.

[24] C. H. Pui, F. G. Behm, and W. M. Crist, "Clinical and biologic relevance of immunologic marker studies in childhood acute lymphoblastic leukemia," Blood, vol. 82, no. 2, pp. 343-362, 1993.

[25] B. H. Pollock, M. R. Debaun, B. M. Camitta et al., "Racial differences in the survival of childhood B-precursor acute lymphoblastic leukemia: a Pediatric Oncology Group study," Journal of Clinical Oncology, vol. 18, no. 4, pp. 813-823, 2000.

[26] J. J. Shuster, P. Wacker, J. Pullen et al., "Prognostic significance of sex in childhood B-precursor acute lymphoblastic leukemia: a Pediatric Oncology Group study," Journal of Clinical Oncology, vol. 16, no. 8, pp. 2854-2863, 1998.

[27] N. S. Kadan-Lottick, K. K. Ness, S. Bhatia, and J. G. Gurney, "Survival variability by race and ethnicity in childhood acute lymphoblastic leukemia," Journal of the American Medical Association, vol. 290, no. 15, pp. 2008-2014, 2003.

[28] S. Bhatia, H. Sather, J. Zhang, M. Trigg, P. Gaynon, and L. Robison, "Ethnicity and survival following childhood acute lymphoblastic leukemia (ALL): follow-up of the Children's Cancer Group (CCG) cohort," in Proceedings of the American Society of Clinical Oncology (ASCO '99), vol. 18, Abstract no. 2190, 1999.

[29] MRC, "Report to the Medical Research Council by the Working Party on Leukemia in childhood: effects of varying radiation schedule, cyclophosphamide treatment, and duration of treatment in acute lymphoblastic leukemia," British Medical Journal, vol. 2, no. 6140, pp. 787-791, 1978.

[30] H. Sather, D. Miller, and M. Nesbit, "Differences in prognosis for boys and girls with acute lymphoblastic leukaemia," The Lancet, vol. 1, no. 8223, pp. 739-743, 1981.

[31] M. Lanning, S. Garwicz, H. Hertz et al., "Superior treatment results in females with high-risk acute lymphoblastic leukemia in childhood," Acta Paediatrica, vol. 81, no. 1, pp. 66-68, 1992.

[32] M. E. Nesbit Jr., H. N. Sather, and L. L. Robison, "Randomized study of 3 years versus 5 years of chemotherapy in childhood acute lymphoblastic leukemia," Journal of Clinical Oncology, vol. 1, no. 5, pp. 308-316, 1983.

[33] A. Reiter, M. Schrappe, W. D. Ludwig et al., "Chemotherapy in 998 unselected childhood acute lymphoblastic leukemia patients. Results and conclusions of the multicenter trial ALLBFM 86," Blood, vol. 84, no. 9, pp. 3122-3133, 1994.

[34] MRC, "The Medical Research Council's working party on leukemia in childhood: duration of chemotherapy in childhood acute lymphoblastic leukemia," Medical and Pediatric Oncology, vol. 10, pp. 511-520, 1982.

[35] P. Imbach, A. Fuchs, W. Berchtold et al., "Boys but not girls with T-lineage acute lymphocytic leukemia (ALL) are different from children with B-progenitor ALL: population-based data results of initial prognostic factors and long-term event-free survival," Journal of Pediatric Hematology/Oncology, vol. 17, no. 4, pp. 346-349, 1995.

[36] J. M. Chessells, S. M. Richards, C. C. Bailey, J. S. Lilleyman, and O. B. Eden, "Gender and treatment outcome in childhood lymphoblastic leukaemia: report from the MRC UKALL trials," British Journal of Haematology, vol. 89, no. 2, pp. 364372, 1995.

[37] G. Gustafsson and A. Kreuger, "Sex and other prognostic factors in acute lymphoblastic leukemia in childhood," American Journal of Pediatric Hematology/Oncology, vol. 5, no. 3, pp. 243-250, 1983.

[38] A. S. Smith et al., "Leukemia, SEER pediatric monograph, 1975-1995,” http://seer.cancer.gov/publications/childhood/ leukemia.pdf.

[39] C. H. Pui, J. M. Boyett, M. V. Relling et al., "Sex differences in prognosis for children with acute lymphoblastic leukemia," Journal of Clinical Oncology, vol. 17, no. 3, pp. 818-824, 1999.

[40] R. Marcos-Gragera, C. Allemani, C. Tereanu et al., "Survival of European patients diagnosed with lymphoid neoplasms in 2000-2002: results of the HAEMACARE project," Haematologica, vol. 96, no. 5, pp. 720-728, 2011.

[41] Y. Xie, S. M. Davies, Y. Xiang, L. L. Robison, and J. A. Ross, "Trends in leukemia incidence and survival in the United States (1973-1998)," Cancer, vol. 97, no. 9, pp. 2229-2235, 2003.

[42] G. M. Dores, S. S. Devesa, R. E. Curtis, M. S. Linet, and L. M. Morton, "Acute leukemia incidence and patient survival among children and adults in the United States, 2001-2007," Blood, vol. 119, no. 1, pp. 34-43, 2012.

[43] L. Holmes Jr., J. Hossain, M. Desvignes-Kendrick, and F. Opara, "Sex variability in pediatric leukemia survival: large cohort evidence," ISRN Oncology, vol. 2012, article 439070, 2012. 


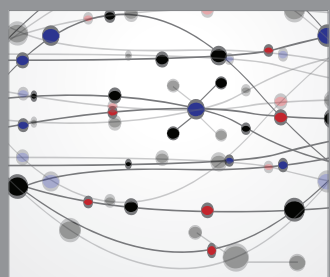

The Scientific World Journal
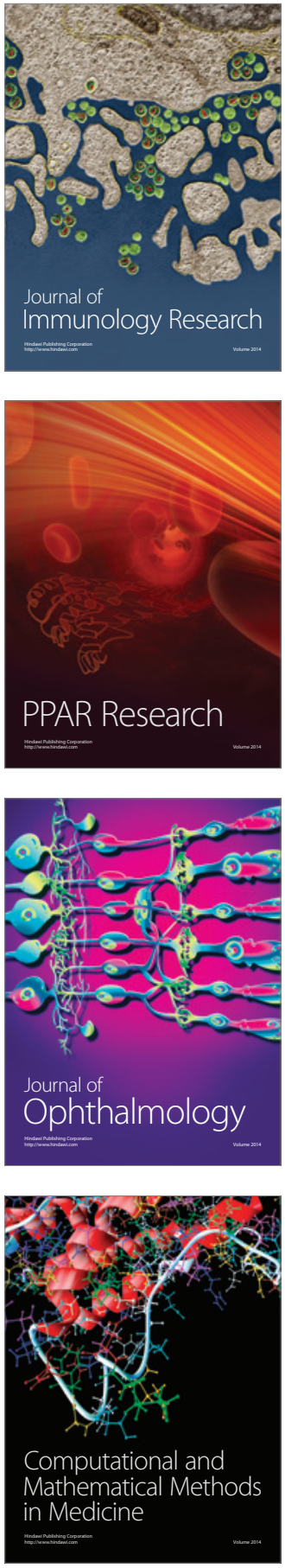

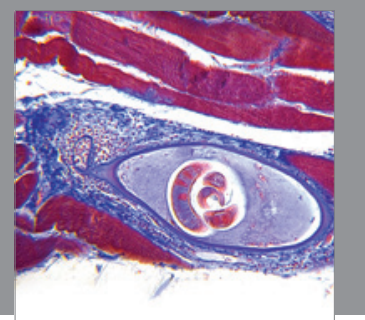

Gastroenterology

Research and Practice
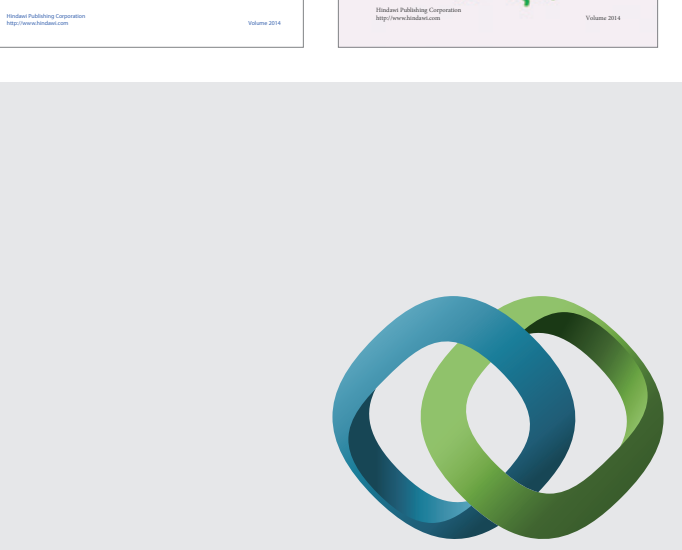

\section{Hindawi}

Submit your manuscripts at

http://www.hindawi.com
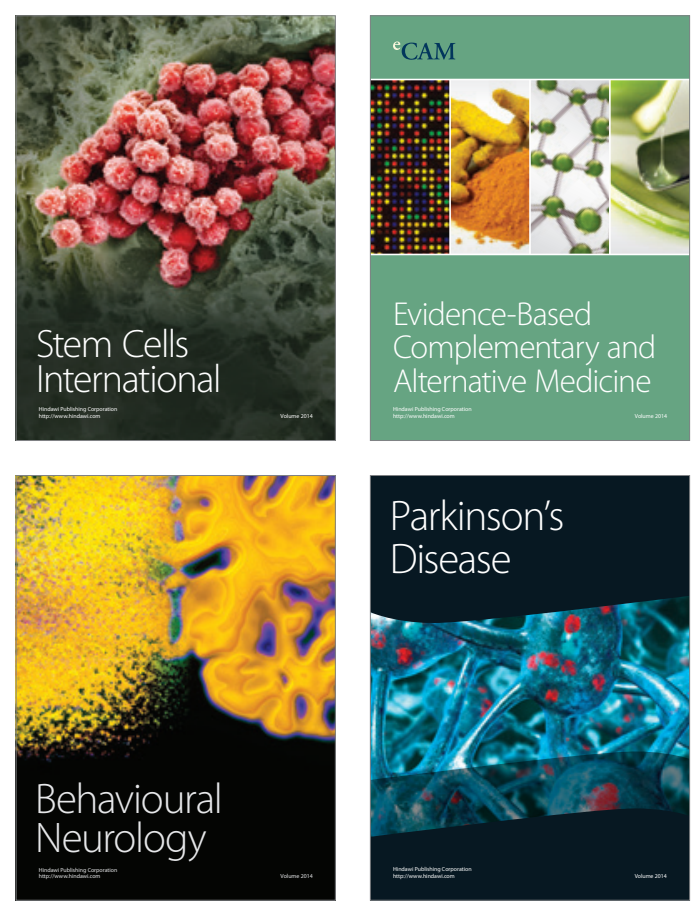

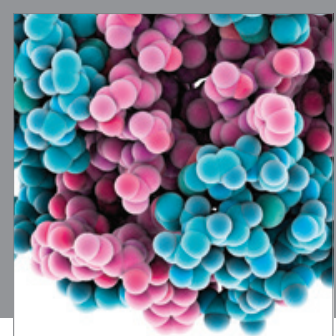

Journal of
Diabetes Research

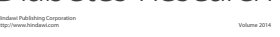

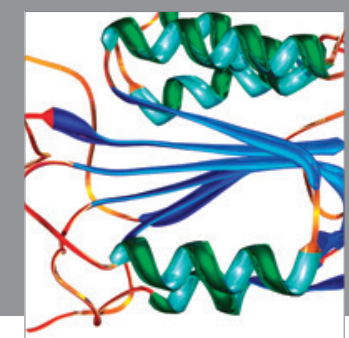

Disease Markers
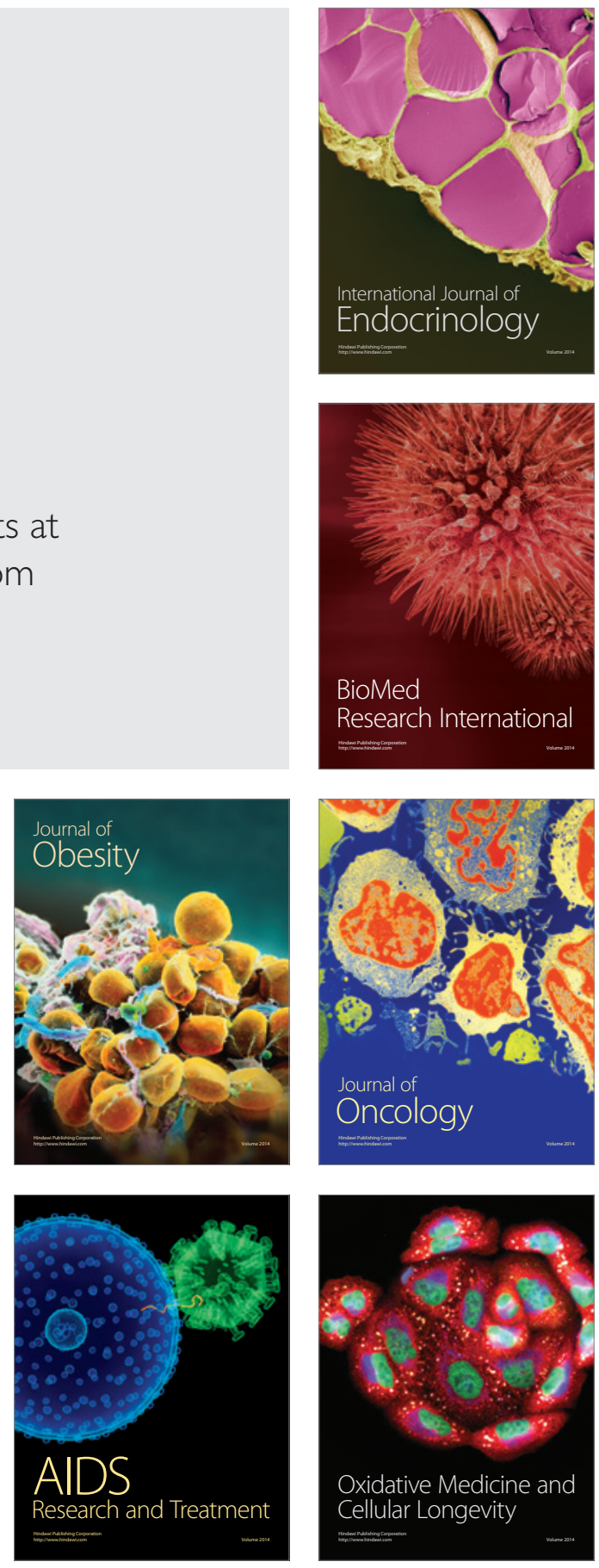